\title{
Design procedure for dual air handling unit of air-conditioning system
}

\author{
Azizuddin Abd Aziz ${ }^{1^{*}}$, Daisuke Sumiyoshi ${ }^{2}$, Yasunori Akashi ${ }^{3}$ \\ ${ }^{1}$ Faculty of Mechanical Engineering, University Malaysia Pahang, Malaysia \\ ${ }^{2}$ Department of Architecture, Faculty of Human - Environment Studies, Kyushu University, Japan \\ ${ }^{2}$ Department of Architecture, Graduate School of Engineering, The University of Tokyo, Japan
}

\begin{abstract}
The use of conventional air-conditioning system in tropical climate is ineffective to reduce the humidity. In a typical application, the indoor temperature has to be overcooled to decrease the humidity which has an inherent effect of high energy consumption. The introduction of dual air handling unit (AHU) is the answer to high humidity environment. Each AHU is tasked to control the parameter of temperature and humidity respectively according to the desired value. In this paper, the objective is to design the procedure of sizing the dual AHU so that the control system could run efficiently. Basically, eight (8) steps are necessary to size the dual AHU system and the procedure requires sequential manner. Namely, the design process are indoor design condition, fresh air flow, outdoor design condition, room cooling load, capacity of both AHUs, supply air temperature of second AHU, supply air temperature of first AHU and the enthalpy of both AHUs. The design procedure also requires a psychrometric chart to indicate the air thermal condition throughout the cycle of the air-conditioning system. In conclusion, the proposed design procedure is simple yet effective for the application of dual AHU system to handle the excessive latent heat environment.
\end{abstract}

\section{Introduction}

Humidity is one of the factors affecting the thermal comfort in tropical climate. The use of conventional air-conditioning system is deemed ineffective since it only responds to the sensible heat requirement of the conditioned space. In tropical environment however, the latent heat plays a major role in the cooling load and therefore a better dehumidification system is required. Investigations in non-residential buildings [1-4] revealed that the general temperature set-point was around $22-23.5^{\circ} \mathrm{C}$, which gives a measured relative humidity of around $45-65 \%$. Overcooling technique is used to combat the humidity resulting in much lower temperature is observed in the conditioned room. Unfortunately, it was the only option offered by conventional air-conditioning system as a slight increase in the set-point will render an uncomfortable humidity condition of the occupants. As a result, the problem continues to affect the energy consumption of the building.

\footnotetext{
*Corresponding author: azizuddin@ump.edu.my
} 
A new air-conditioning system design consists of two air handling units (AHU) to control the temperature and humidity simultaneously has been presented [5]. The schematic diagram of the proposed system in variable-air-volume configuration is shown in Figure 1. In short, AHU1 is given the task to control the room temperature while AHU2 is assigned to control the indoor humidity. Simulation results shows that the system is able to remove the sensible and latent heat efficiently.

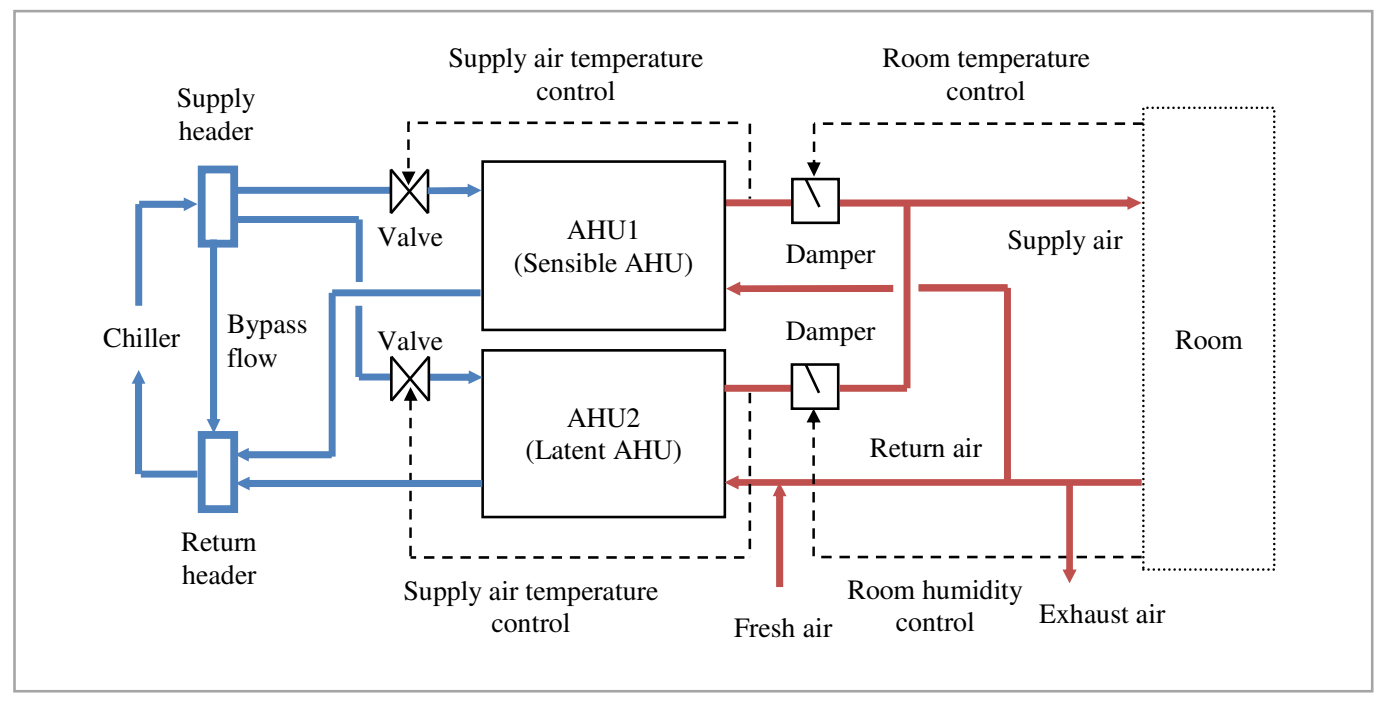

Figure 1. Schematic diagram of the proposed system

In real practice, air-conditioning designer utilizes manual calculation method to come out with a decent sizing of system equipment. The purpose this paper is to clarify the guidelines for the design of dual AHU system using manual calculation. There are several steps of design procedure which is necessary to be performed:
i. Indoor design condition
ii. Outdoor design condition
iii. Room cooling load
iv. Capacity of both AHUs
v. Supply air temperature of AHU2
vi. Supply air temperature of AHU1
vii. Enthalpy of both AHUs

\section{Design procedure}

The steps of design procedure are explained with the aid of figures and tables. Model building in Figure 2 is used as the example for the calculation to enhance the design method comprehension. 


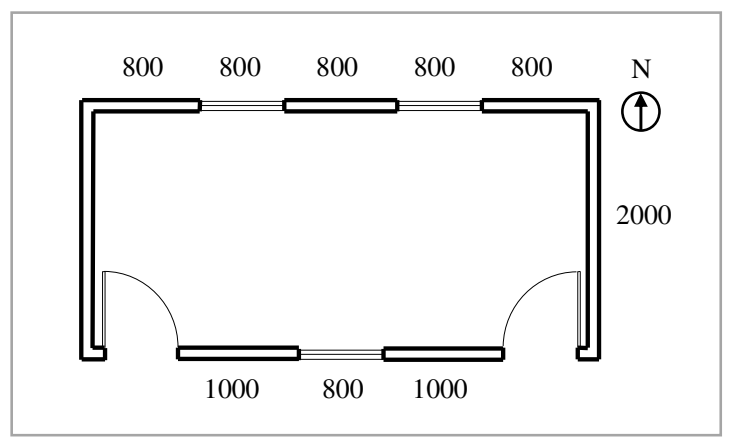

Figure 2. Model building with dimensions in $\mathrm{mm}$

Step i. - Indoor design condition. The necessity to change the indoor condition of tropical buildings has been discussed thoroughly in the early stages of this paper. The particular indoor condition is chosen based on two reasons; to improve the thermal comfort of the occupants and to reduce the energy consumption of existing buildings. For the sake of argument, the following room condition is chosen.

Room temperature: $26^{\circ} \mathrm{C}$

Room humidity: $50 \%$

Coincident absolute humidity: $0.0105 \mathrm{~kg} / \mathrm{kg}$ dry air

In Malaysia, the minimum requirement of fresh air flow inside a non-residential building is governed by the law [6]. For the case of air-conditioned office space, the minimum outdoor air required is $16.8 \mathrm{~m}^{3} / \mathrm{h}$ per person.

Step ii. - Outdoor design condition. Unlike normal air-conditioning design method that utilizes the hot outdoor condition only, the proposed system also takes the humid condition into account. Malaysian Standard MS1525 has outlined the following outdoor design condition for the hottest condition [7]:

Dry bulb temperature: $\quad 33.3^{\circ} \mathrm{C}$

Wet bulb of temperature: $\quad 27.2^{\circ} \mathrm{C}$

Coincident relative humidity: $63.2 \%$

Absolute humidity: $\quad 0.0205 \mathrm{~kg} / \mathrm{kg}$ dry air

The necessary information on the humid condition is found in the ASHRAE Handbook that provides the particular data of major cities around the world. Table 1 shows the information of Kuala Lumpur [8].

Table 1. Outdoor design condition of Kuala Lumpur

\begin{tabular}{|c|l|c|}
\hline Dehumidification & \multicolumn{1}{|c|}{ Parameter } & Temperature $\left({ }^{\circ} \mathbf{C}\right)$ \\
\hline \multirow{2}{*}{$0.4 \%$} & Dew point & 26.2 \\
\cline { 2 - 3 } & Mean coincident dry bulb & 29.3 \\
\hline \multirow{2}{*}{$1 \%$} & Dew point & 26.1 \\
\cline { 2 - 3 } & Mean coincident dry bulb & 29.2 \\
\hline
\end{tabular}


The percentage value in the table represents the annual cumulative occurrence of the outdoor condition. For instance, $0.4 \%$ means that on a yearly basis, the particular outdoor condition happens at a total of $0.4 / 100 \times(365 \times 24)=35.0$ hours of cumulative occurrence. If $0.4 \%$ occurrence is chosen by the air-conditioning system designer, the coincident relative humidity and absolute humidity are $83.4 \%$ and $0.0216 \mathrm{~kg} / \mathrm{kg}$ dry air respectively. The difference of relative humidity between hot and humid condition is notably significant.

Step iii. - Room cooling load. In this procedure, the cooling load of the room is first calculated according to both hot and humid conditions. The load calculation is similar to the one used in the normal air-conditioning system. Normally, the sensible load for the hot condition is higher than that of the humid condition but the latent load for the hot condition is lower than that of the humid condition. Also, the total cooling load for the hot condition is higher than that of the humid condition. For the sake of argument, the cooling load of a fictional $800 \mathrm{~m}^{2}$ floor area room is calculated using both hot and humid outdoor condition. The results are shown in Table 2. It is observed that the sensible load is reduced $29.4 \%$, and the latent load is increased $17.8 \%$ by using humid outdoor condition. Subsequently, the humid condition lessened the sensible heat factor (SHF) by $14.9 \%$.

Table 2. Room cooling load

\begin{tabular}{|l|c|c|}
\hline \multicolumn{1}{|c|}{ Parameter } & Hottest & Most humid \\
\hline Sensible $(\mathrm{kW})$ & 49.23 & 34.74 \\
\hline Latent $(\mathrm{kW})$ & 17.33 & 20.41 \\
\hline Total $(\mathrm{kW})$ & 66.56 & 55.15 \\
\hline Sensible heat factor & 0.74 & 0.63 \\
\hline
\end{tabular}

Step iv. - Capacity of both AHUs. The size of AHU2 is directly chosen by the designer without any calculation. However, there are limitations in the size combination of AHU1 and AHU2 as per earlier discussion. As a result, the range of acceptable AHU size ratio is a function of indoor latent heat as shown in Figure 3 for the constant-air-volume system. Therefore, the chosen capacity of AHU2 must be within the acceptable range or else the system not be able to function effectively. For instance, the SHF for humid condition from Table 6 is 0.63 . According to Figure 3, the acceptable AHU size ratio of 0.63 lies between nearly $20: 80$ and 45:55.

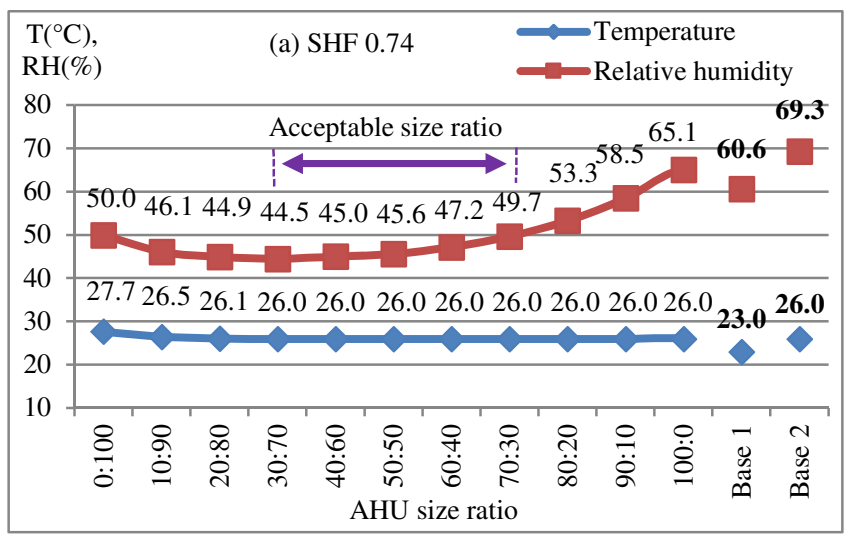

Figure 3. AHU acceptable size ratio 
If size ratio 30:70 is chosen, the AHU2 capacity can be directly calculated as follows:

AHU2 capacity $=0.7 \times 66.56 \mathrm{~kW}=46.59 \mathrm{~kW}$

Note that the total cooling load of $66.56 \mathrm{~kW}$ of hot condition is used in the calculation instead of $55.15 \mathrm{~kW}$ of humid condition to ensure that the AHUs always have enough capacity.

Step v. - Supply air temperature of AHU2. The determination of supply air temperature of AHU2 does not involve any calculation. It is up to the air-conditioning designer to choose the preferred value. However, as the function of AHU2 or Latent AHU is to provide dehumidification to the conditioned room, a low temperature is required for the moisture removing process. In a typical application, the chiller produces chilled water at $7^{\circ} \mathrm{C}$. Therefore, AHU2 supply air temperature can be chosen from $8^{\circ} \mathrm{C}$ to $14^{\circ} \mathrm{C}$.

Step vi. - Supply air temperature of AHU1. The method to determine the supply air temperature of AHU1 involves the use of a psychrometric chart. Based on the Figure 4, the design technique is described as follows:

i. Draw the line between the outdoor humid condition of $29.3^{\circ} \mathrm{C} \mathrm{DB} / 83 \% \mathrm{RH}$ and room condition of $26^{\circ} \mathrm{C} \mathrm{DB} / 50 \% \mathrm{RH}$.

ii. Draw the SHF line of 0.63 from AHU2 supply air at 95\% RH until the horizontal line of $0.0105 \mathrm{~kg} / \mathrm{kg}$ dry air of room condition. The intersection point of represents AHU1 supply air temperature and marked as point (1) in Figure 4.

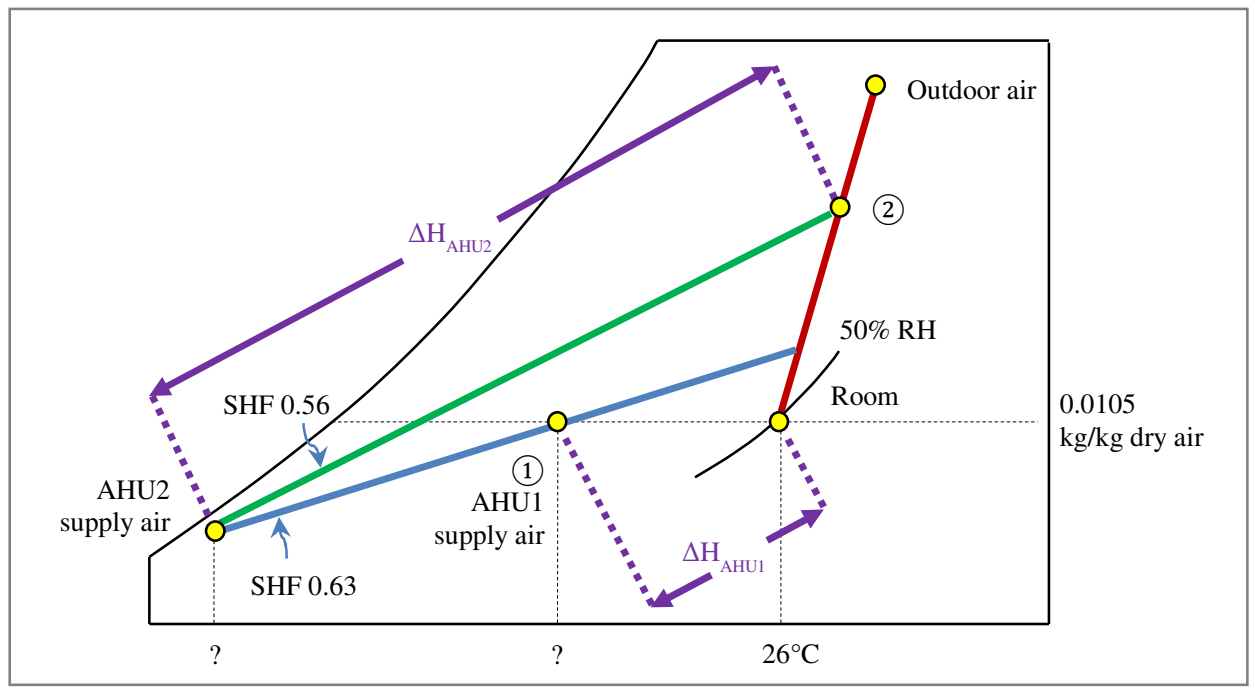

Figure 4. Determination of supply air temperature using psychrometric chart

The difference in choices of AHU2 supply air leads to the outcome variation of AHU1 supply air. Table 9 shows the options for the supply air temperature combination between both AHUs. 
Table 9. Options for supply air temperature combination for SHF 0.63

\begin{tabular}{|c|c|}
\hline \multicolumn{2}{|c|}{ Temperature $\left({ }^{\circ} \mathbf{C}\right)$} \\
\hline AHU2 & AHU1 \\
\hline 8.0 & 24.0 \\
\hline 10.0 & 22.0 \\
\hline 12.0 & 19.5 \\
\hline
\end{tabular}

Step vii. - Enthalpy of both AHUs. The enthalpy determines the flow rate of the AHUs. The capacity of AHU2 has been calculated in Step D. Therefore, the SHF of AHU2 is decided by matching the required latent heat load of the humid condition. The details are as follows:

AHU2 capacity $=46.59 \mathrm{~kW}$, latent load $=20.41 \mathrm{~kW}$

Therefore, $\mathrm{SHF}=0.56$

As shown in Figure 4, the next step is to draw a line of SHF 0.56 from AHU2 supply air temperature and $95 \%$ RH until it intersects the fresh air line at point (2). The difference between these two points represents AHU2 enthalpy. On the other hand, AHU1 enthalpy is defined by the difference between point (1) and the room condition.

\section{Conclusion}

The proposal of manual design of dual air handling unit of air conditioning system is presented in this paper. There are altogether 7 steps required to complete the equipment sizing procedure in sequential order. Unlike the conventional system where the design is based on the hottest outdoor condition, the proposed air-conditioning system utilises the humid condition as well to handle the latent heat.

The authors are thankful to Universiti Malaysia Pahang for providing the necessary support for this paper under the research no. RDU170385, as well as to Energy Sustainability Focus Group (ESFG) members who assisted the research.

\section{References}

1. Yau, Y.H., International Journal of Mechanical and Materials Engineering, vol.3, no.2, pp.119-126 (2008)

2. Sulaiman, R., Kamaruzzaman, S.N., Rao, S.P., Pitt, M., Journal of Surveying, Construction \& Property, vol.2, no.1, pp.75-80 (2011)

3. Yau, Y.H., Chew, B.T., Saifullah, A., Thermal comfort in lecture halls in the tropics, International Symposium on Heating, Ventilation and Air Conditioning, pp.309-317, (2011) 
4. Azizuddin, A.A, Sumiyoshi, D., Akashi, Y, Journal of Habitat Engineering and Design, vol.5, no.2, pp.11-21 (2013)

5. Azizuddin A. A. , D. Sumiyoshi, Y. Akashi, J. Building Eng., vol.11, pp.9-16 (2017)

6. Malaysian Uniform Building by Laws, Article 12(1) Third Schedule (1984)

7. Department of Standards Malaysia, MS1525:2007 Code of Practice on Energy Efficiency for Non-Residential Buildings (2007)

8. ASHRAE Handbook: Fundamentals, American Society of Heating, Refrigeration and Air-conditioning Engineers, (Atalanta, 2009) 